\title{
Sonicated extracts from the Quorn fermentation co-product as oil-lowering emulsifiers and foaming agents
}

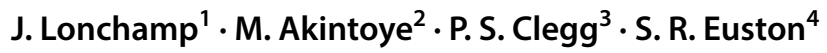

Received: 13 September 2019 / Revised: 15 January 2020 / Accepted: 18 January 2020 / Published online: 1 February 2020

(c) The Author(s) 2020

\begin{abstract}
This study assessed the impact of sonication on the structure and properties of a functional extract (retentate 100 or R100) from the Quorn fermentation co-product (centrate). In a previous study, we reported that the R100 fraction displayed good foaming, emulsifying and rheological properties. Sonication of a R100 solution led to the breakdown of the large hyphal structures characteristic of this extract into smaller fragments. Foams prepared with sonicated R100 displayed a higher foaming ability than with untreated R100 and a high foam stability but lower than untreated R100 ones. Oil-in-water emulsions prepared with sonicated R100 displayed smaller oil droplet size distributions than with untreated R100. Confocal micrographs suggested that small fungal fragments contributed to the stabilisation of oil droplets. 50\% oil-reduced R100 emulsions were prepared by mixing R100 emulsions (untreated or sonicated) with a sonicated R100 solution at a 1:1 ratio. Smaller oil droplet size distributions were reported for the oil-reduced emulsions. These results showed that the addition of small hyphal fragments or surface-active molecules and molecular aggregates released during sonication contributed to the formation and stabilisation of smaller oil droplets. This study highlighted the potential to modulate the structure, emulsifying and foaming properties of functional extracts from the Quorn fermentation co-product by sonication and the potential of these extracts as oil-lowering agents in emulsion-based products through the reduction of oil droplet size and their stabilisation.
\end{abstract}

J. Lonchamp

JLonchamp@qmu.ac.uk

1 Present Address: School of Health Sciences, Queen Margaret University, Queen Margaret University Drive, Edinburgh EH21 6UU, UK

2 Quorn Foods, Station Road, Stokesley TS9 7BR, UK

3 School of Physics and Astronomy, The University of Edinburgh, Peter Guthrie Tait Road, Edinburgh EH9 3FD, UK

4 Institute of Mechanical, Process and Energy Engineering, School of Engineering and Physical Sciences, Heriot-Watt University, Edinburgh EH14 4AS, UK 


\section{Graphical abstract}

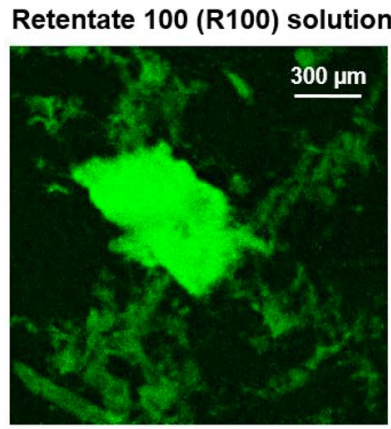

Aggregated hyphal structures

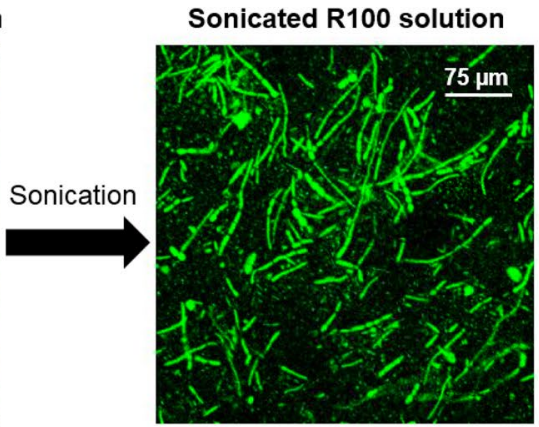

Hyphal fragments
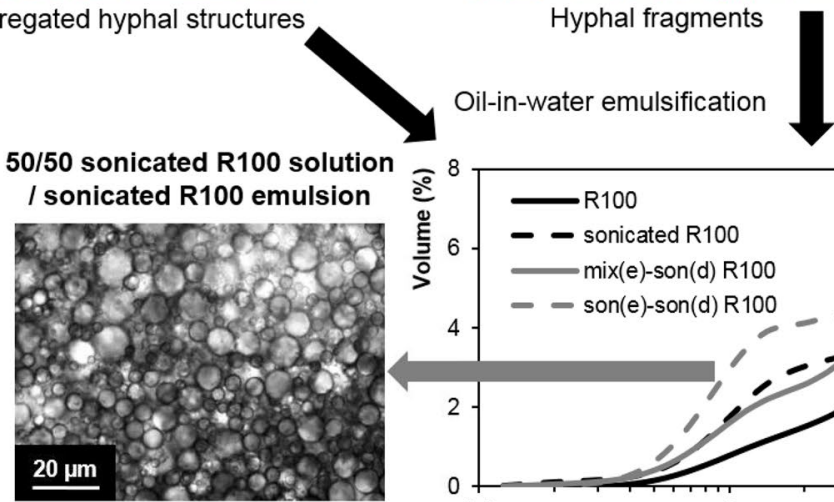

Oil-reduced emulsion

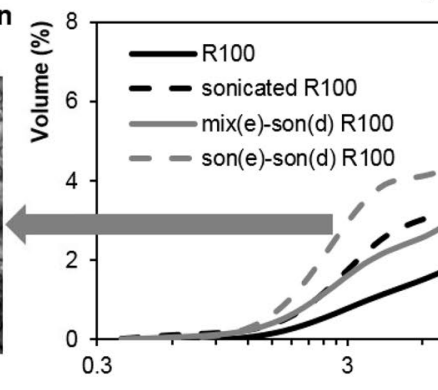

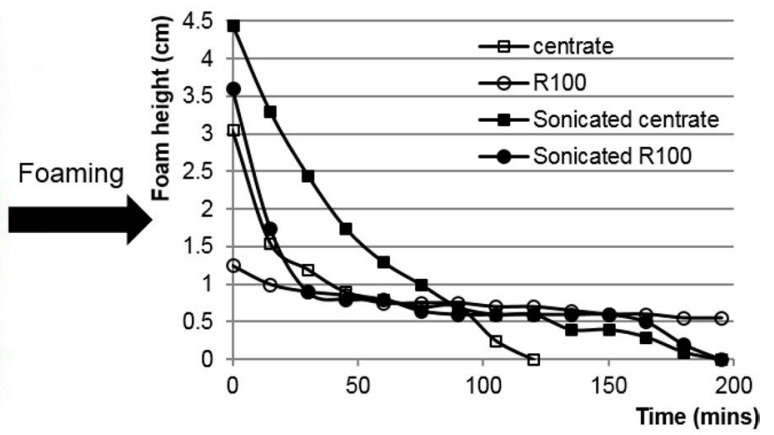

Enhanced foaming properties

Native R100 emulsion

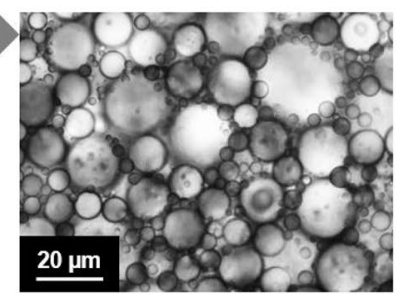

Oil droplet diameter $(\mu \mathrm{m})$

Keywords Quorn $\cdot$ Co-product $\cdot$ Centrate $\cdot$ Sonication $\cdot$ Emulsion $\cdot$ Foam

\section{Abbreviations \\ R100 Retentate 100 \\ NCM Nitrogen-containing material \\ WPC Whey protein concentrate \\ RI Refractive index}

\section{Introduction}

The World Health Organization (WHO) and the Food and Agriculture Organization of the United Nations (FAO) have recommended a reduction in daily intake of total fat to achieve a level of $15-30 \%$ of dietary energy $[1,2]$. As a response, academia and the food industry have been investigating a number of strategies to reduce the total fat content of food products while maintaining their structural and organoleptic properties. Of these, increasing the creaminess and satiety of emulsion-based formulations via the reduction of oil droplet size allows the possibility of reducing the oil content in products whilst maintaining hedonic and satiating properties. Oil-in-water emulsions (dispersions of oil into water as droplets stabilised by an emulsifier) are common food microstructures found in a wide range of products including sauces, condiments, spreads, dressings and desserts. The impact of oil droplet size on sensory perception and satiety has been explored in a series of nutritional intervention studies. A reduction in droplet size from 50 to $2 \mu \mathrm{m}$ in a model oil-in-water drink formulation resulted in a significant $12.3 \%$ reduction in lunch intake among participants [3]. In another study, the creamy mouthfeel of a similar model drink formulation increased significantly as the oil droplet size was decreased from 50 to 11, 6, 2 and $0.2 \mu \mathrm{m}$, while the hedonic appeal and fullness sensation increased and the hunger sensation recorded at $1 \mathrm{~h}$ postprandial decreased [4]. With regards to this strategy, the food industry is investigating novel sustainable sources of functional ingredients and novel processes to increase their functionality with a view to reducing the oil droplet size in emulsion-based formulations.

In this context, the production of mycoprotein by Marlow Foods for use in their meat alternative product Quorn is a potential source of sustainable functional ingredients. The term mycoprotein refers to the high-protein biomass produced by fermentation of the fungus Fusarium venenatum A3/5 (ATCC PTA-2684) by Marlow Foods, which forms the basis of their Quorn brand products. Mycoprotein contains all essential amino acids [5] and the net protein utilisation value of Fusarium venenatum mycoprotein is comparable to 
that of milk [6]. Moreover, the fermentation of starch into protein by $F$. venenatum results in $90 \%$ lower emission of greenhouse gases and benefits in terms of land and water footprints in comparison with beef products [7].

Following fermentation, the broth undergoes an RNAreduction step during which it is first heat shocked above $68{ }^{\circ} \mathrm{C}$ for $30-45 \mathrm{~min}$, further heated at $90{ }^{\circ} \mathrm{C}$ and finally centrifuged [8]. This heat-shock step stops growth, disrupts ribosomes and activates endogenous RNAases which breakdown cellular RNA to nucleotides [8]. The resulting solid deposit (mycoprotein biomass) is then processed into a dough ready for conversion to the meat-like texture characteristic of Quorn foods. However, the heat-shock RNAreduction step also induces diffusion of a fraction of the cell components through the cell wall [8]. The liquid supernatant (centrate) generated by the subsequent centrifugation step thus contains residual hyphal biomass, carbohydrates, nucleotides and proteins as well as the residues of the fermentation feedstock and is currently an unexploited co-product stream.

In a previous study, we reported that an extract (retentate 100 or R100) obtained via a $100 \mathrm{kDa}$ ultrafiltration of the centrate displayed good foaming stability, emulsifying and rheological properties (viscosity, viscoelasticity and gelation) [9]. R100 solutions displayed high viscosity, while heat-induced hydrogels of R100 solutions exhibited high viscoelasticity. R100 foams displayed high stability while oilin-water R100 emulsions showed small and stable oil droplet size distributions. This study also reported that heat treatment $\left(80^{\circ} \mathrm{C}\right.$ for $\left.30 \mathrm{~min}\right)$ of an R100 solution increased its foaming ability, foam stability and emulsion stability. Large hyphal aggregates were reported in R100, contributing to its high viscosity and viscoelasticity and to foam and emulsion stabilisation. In addition, tensiometry measurements showed that interfacially active molecules present in R100 formed a rigid film at the oil/water interface. A number of functional metabolites and proteins that could have also contributed to the functional properties reported were identified in the centrate. These included a cerato-platanin surfactant protein, cell membrane constituents (phospholipids, sterols, glycosphingolipids, sphingomyelins), cell wall constituents (chitin, chitosan, proteins) and guanine and guanine-based nucleosides and nucleotides.

Although centrate extracts have been shown to be functional, it is unknown whether this functionality can be improved through further processing. One of the novel processes used to modulate and/or increase the functionality of ingredients is the application of ultrasound through sonication. Ultrasound treatment has a wide range of applications in the food industry including homogenisation, extraction, reduction of particle size, cell destruction and dispersion of aggregates [10]. Of particular interest for this study is the reported breakdown of cell walls and the subsequent release of intracellular material into the medium as a result of the cavitation of bubbles and their implosion during sonication $[11,12]$. Sonication has more recently been applied to enhance the foaming and emulsifying properties of functional ingredients. The sonication of a range of proteins including egg white proteins, bovine serum albumin, soy proteins as well as a hydrophobin HFBII extract from the fungus Trichoderma reesei led to the stabilisation of air bubbles in solution, following which the subsequent mixing with an oil-in-water emulsion resulted in a triphasic air/oil/water system with potential for oil reduction [13-15].

The current study aimed to assess the possible modulation of the foaming and emulsifying properties of the R100 extract by sonication. In particular, the impact of the application of ultrasound on the large hyphal structures present in R100 and the potential of sonicated R100 as emulsifier in an oil-reduced emulsion system were investigated.

\section{Materials and methods}

\section{Sample preparation}

Centrate samples were collected from the Marlow Foods fermenter site at Belasis, Billingham (North Yorkshire) and frozen before analysis. Following thawing, the centrate underwent a series of ultrafiltration steps using a range of Vivaflow 200 cross-flow cassettes (Sartorius, UK) connected to a Masterflex Easy-Load peristaltic pump (Sartorius, UK). Following an initial $100 \mathrm{kDa}$ ultrafiltration, the resulting retentate 100 or R100 (composed of material larger than $100 \mathrm{kDa}$ ) appeared as foamy, while the filtrate 100 underwent a further $50 \mathrm{kDa}$ followed by a $5 \mathrm{kDa}$ membrane, resulting in a retentate $\mathrm{R} 100+50$ (material between 50 and $100 \mathrm{kDa}$ ) and a retentate $\mathrm{R} 100+50+5$ (material between 5 and $50 \mathrm{kDa}$ ) fractions. Samples of the centrate and resulting retentates were freeze-dried in a Super Modulyo unit (Edwards, UK).

\section{Nitrogen content}

We previously reported that a wide range of functional molecules present in centrate and concentrated in the R100 fraction contained nitrogen, including fungal cell membrane and cell wall constituents such as phospholipids, glycosphingolipids, sphingomyelins, chitin, chitosan and proteins [9]. In that regard, the nitrogen-containing material (NCM) content was measured using the Kjeldahl method (Lynch et al. 1998) to provide a guideline for preparation of standardised sample quantities for functional tests [16]. Sets of $0.1 \mathrm{~g}$ of EW and R100 were digested in concentrated sulphuric acid (92\%) using a Kjeltec Basic Digestion Unit 20 (Foss, UK) at $440{ }^{\circ} \mathrm{C}$ in the presence of a selenium catalyst. Distillation of 
the digested samples into boric acid was carried out using a Tecator Kjeltec 8100 Manual Distillation Unit (Foss, UK). The distilled samples were then titrated using $0.1 \mathrm{~N}$ hydrochloric acid. The \% nitrogen was calculated using the following formula:

$\%$ Nitrogen $=\frac{\text { Titration volume }(\mathrm{ml}) \times 14.007}{\text { Sample weight }(\mathrm{g}) \times 100}$

The $\%$ nitrogen obtained was then multiplied by the general conversion factor of 6.25 recommended for mycoprotein biomass [17] to obtain a $\%$ nitrogen-containing material (NCM). Measurements were repeated three times.

\section{Sonication}

$1 \% \mathrm{w} / \mathrm{w}$ NCM solutions of the centrate fractions were prepared in deionised water and stirred for $1 \mathrm{~h}$. The solutions were sonicated for $3 \mathrm{~min}$ at $20 \mathrm{kHz}, 500 \mathrm{~W}$ and $50 \%$ amplitude using a Sonics Vibra-Cell VCX-500 probe sonicator (Sonics, UK).

\section{Particle size distribution}

The particle size distribution of the $1 \%$ w/w NCM untreated and sonicated centrate fraction solutions was assessed by laser light diffraction and dynamic light scattering. At the micrometre level, the average particle size distribution $(D[3,2]$ or surface weighted mean) was measured by laser light diffraction using a Beckman-Coulter LS 13320 particle size analyser (Beckman-Coulter, UK). Since the refractive indexes (RIs) of the different untreated and sonicated centrate fractions were not known, we used a method developed by Hayakawa et al. [18] and Saveyn et al. [19] to determine the optimal RI to use to derive particle size data for each sample. The particle size distributions of all samples were first measured using an RI of 1.40 and were then recalculated using RIs ranging from 1.35 to 1.80 with an interval of 0.05 via the associated LS 13320 software (Beckman-Coulter, UK). The resulting $D[3,2]$ values from these calculations were then plotted against the RI values for each sample. Based on the graphs obtained, the optimal RI to use for each sample was determined (the criteria used in the determination of the optimal RI are provided in the results section). The laser obscuration was adjusted to $10 \%$ obscuration and triplicate measurements were carried out.

At the nanometre level, the particle size distribution (radius) was measured by dynamic light scattering. The centrate fraction solutions were filtered using a $1 \mu \mathrm{m}$ cut-off membrane, placed in test tubes and sealed. Measurements were performed using a $633 \mathrm{~nm}$ laser with scattered light collected at $90^{\circ}$ from the incident beam direction. The data were processed using an ALV-LSE-5004 correlator and size distributions (radius) were obtained from mass-weighted correlation functions. Measurements were repeated three times.

\section{Foaming properties}

Two sets of $15 \mathrm{~g}$ solutions of the centrate protein fractions $(1 \% \mathrm{w} / \mathrm{w} \mathrm{NCM})$ were prepared in $50 \mathrm{ml}$ glass beakers, which corresponds to an initial volume of $18 \mathrm{~cm}^{3}(1.4 \mathrm{~cm}$ sample height and $4 \mathrm{~cm}$ beaker diameter), and stirred for $1 \mathrm{~h}$. One set of each solution was sonicated, while the other set was left untreated. The solutions were frothed for 1 min using a handheld whisk-type frother (Aerolatte, UK). The height of the resulting foam was measured immediately after whisking and every $10 \mathrm{~min}$ until collapse of the foam. The foaming ability was expressed as the initial height of the foam, while the foam stability was determined as the time needed for the foam to fully collapse. Measurements were conducted at room temperature and repeated twice.

\section{Emulsifying properties}

Two sets of $15 \mathrm{~g}$ solutions of the centrate fractions (standardised to $1 \% \mathrm{w} / \mathrm{w} \mathrm{NCM}$ ) were prepared in deionised water and stirred for $1 \mathrm{~h}$. One set of each solution was sonicated, while the other set was left untreated. Each solution was then mixed with $5 \mathrm{~g}$ of sunflower oil (to obtain a 3:1 aqueous solution to oil phase ratio) and the mixture was homogenised using an IKA T18 Ultra-Turrax high-speed homogeniser (IKA-Werke GmbH, Germany) at 10,000 rpm for $1 \mathrm{~min}$ to produce an oil-in-water emulsion. The average oil droplet size distribution of the centrate fraction emulsions $(D[3,2]$ or surface weighted mean) was measured by laser light diffraction with the refractive index set at 1.474 (corresponding to sunflower oil). The particle size distribution of the centrate fraction solutions $(D[3,2])$ was also measured using the same refractive index (1.474) to assess the potential influence of hyphal material on the oil droplet sizes and distributions obtained for emulsions prepared with centrate fractions.

\section{Reduced-oil emulsions}

The oil-lowering potential of the untreated and sonicated centrate fractions in emulsion-based systems was investigated. Pre-existing emulsion droplets and dispersions were combined as shown in Fig. 1 to explore the contribution of the added emulsifying material to the interface and continuous phase. Two sets of $15 \mathrm{~g}$ solutions of each centrate fraction ( $1 \% \mathrm{w} / \mathrm{w}$ NCM) were stirred for $1 \mathrm{~h}$ (Fig. 1). One set of each solution was sonicated, while the other set was left untreated (stirred). Oil-in-water emulsions were prepared with either the stirred or sonicated dispersions using the Ultra-Turrax homogeniser. The resulting emulsions 


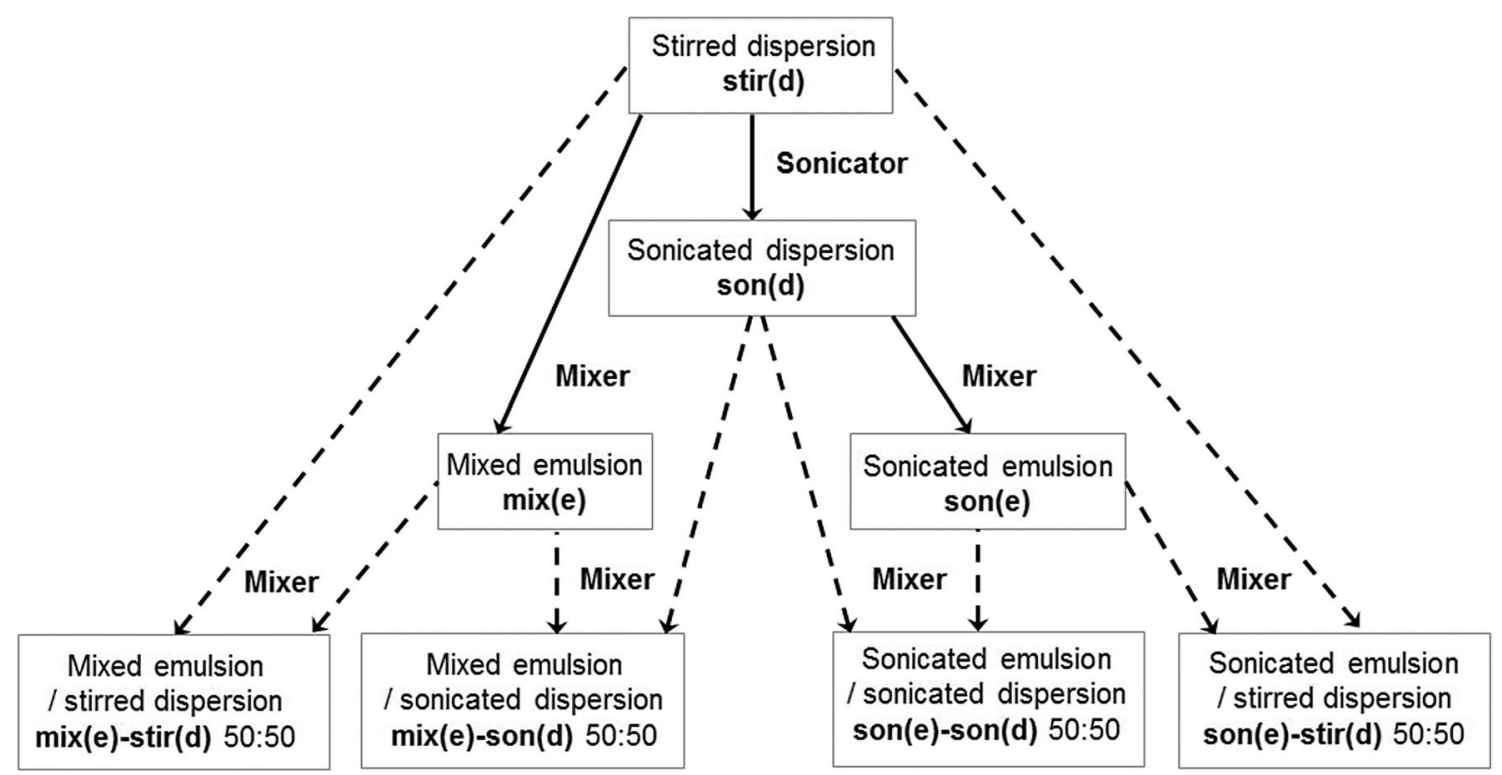

Fig. 1 Reduced-oil emulsion production diagram. $d$ dispersion, $e$ emulsion, stir stirred, son sonicated, mix mixed

were then mixed with either the stirred or sonicated dispersions at a 1:1 ratio using the high-speed homogeniser at $10,000 \mathrm{rpm}$ for $1 \mathrm{~min}$ to produce a range of $15 \mathrm{~g} 50 \%$ oilreduced emulsions. 50\% oil emulsion controls were prepared with untreated and sonicated centrate fractions following the method described in the emulsifying properties section.

\section{Confocal and bright-field microscopy}

Untreated and sonicated centrate fraction solutions, foams and oil-in-water emulsions were imaged using a Leica TCS2 confocal laser scanning microscope (Leica Microsystems, Germany). Images were recorded at a resolution of $512 \times 512$ pixels and analysed using the associated DM SDK version 4.2.1 software. For the imaging of solutions and foams, $1 \%$ w/w NCM solutions of the centrate fractions were supplemented with the fluorescent dye Rhodamine B. For hyphal staining in oil-in-water emulsions, Rhodamine B was added to $1 \% \mathrm{w} / \mathrm{w}$ NCM centrate fraction solutions before mixing with the oil. The dye was excited at $514 \mathrm{~nm}$, the collection range was $600-700 \mathrm{~nm}$ and a $10 \times / 0.25$ dry lens was used. For oil droplet staining in oil-in-water emulsions, traces of Nile Red dye (Sigma Aldrich Co., UK) were added to the oil prior to mixing with the centrate fraction solution. The dye was excited at $549 \mathrm{~nm}$ and fluoresced light was collected at the emission maximum of $628 \mathrm{~nm}$. A $63 \times / 1.40-0.60$ oil lens was used. For the reduced-oil emulsifying experiments microscopic images of centrate fraction emulsions and oilreduced emulsions were obtained using an Olympus BX-50 light microscope equipped with a QImaging QICAM digital camera (Olympus, UK). Emulsions were observed using a $50 \times / 0.5$ lens.

\section{Results and discussion}

\section{Characterisation of untreated and sonicated solutions}

The optimal refractive index (RI) to use to derive particle size distribution data for each centrate fraction sample (untreated and sonicated) was determined using a method developed by Hayakawa et al. [18] and Saveyn et al. [19]. Following the measurement of the particle size distributions $(D[3,2])$ of each sample using an RI of 1.40 , the $D[3,2]$ values were recalculated using RIs ranging from 1.35 to 1.80 with an interval of 0.05 and plotted against RI values for each sample. According to this method [18, 19], the RI corresponding to the first peak of the recalculated particle size is considered to be the optimum for determining the particle size distribution. The $D[3,2]$ values obtained for all the samples increased with RI values up to a certain RI value and then remained constant or decreased (results not shown). The optimal RI values (corresponding to the $D[3,2]$ peak) obtained for untreated centrate, R100 and R100+50+5 solutions were, respectively, $1.38,1.39$ and 1.42 , while the optimal RIs reported for the sonicated centrate, R100 and $\mathrm{R} 100+50+5$ samples were, respectively, 1.40, 1.41 and 1.42 (results not shown).

The particle size distribution of the $1 \% \mathrm{w} / \mathrm{w} \mathrm{NCM}$ untreated and sonicated centrate fraction solutions was then assessed by laser light diffraction at the optimal RI determined for each sample (Fig. 2a). Large particles were reported for untreated R100 solutions (composed of material larger than $100 \mathrm{kDa}$ ), with the highest peak observed at $234 \mu \mathrm{m}$ and particles reported up to $864 \mu \mathrm{m}$. The highest 

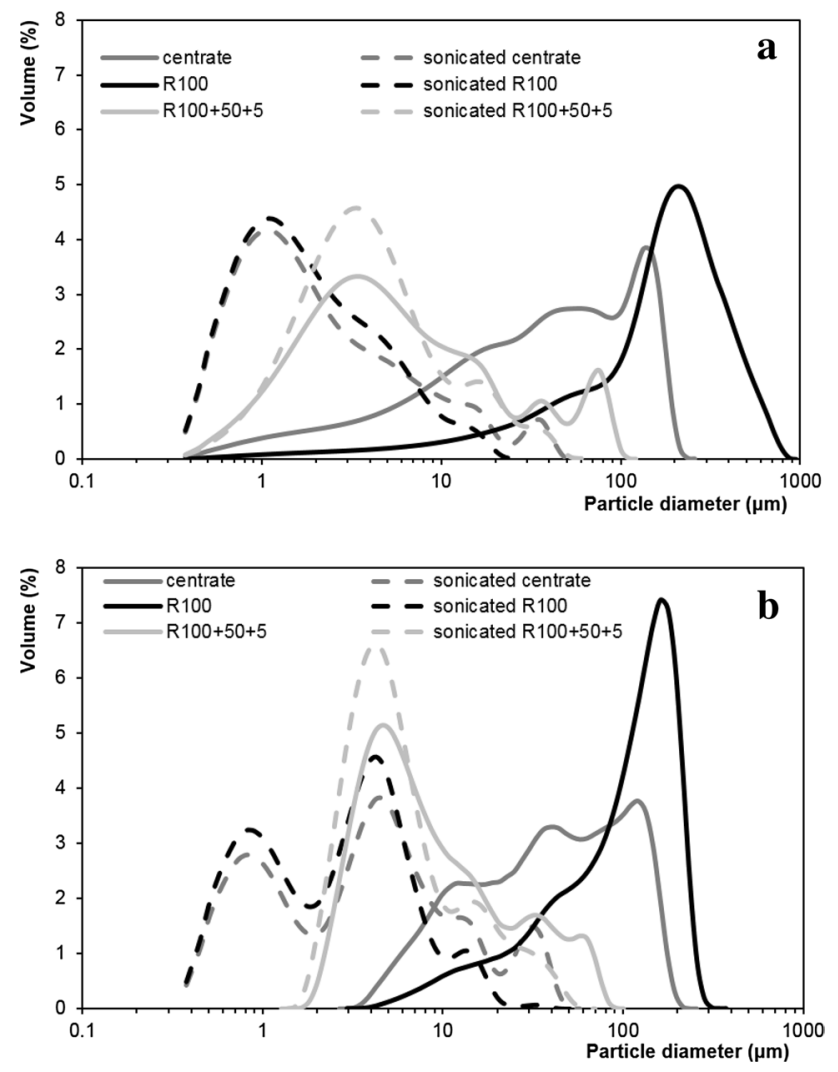

Fig. 2 Particle size distribution of untreated and sonicated centrate fraction solutions measured by laser light diffraction at the optimal refractive index determined for each sample (a) and at a refractive index of 1.474 (b) $(1 \% \mathrm{w} / \mathrm{w} \mathrm{NCM}$, original $\mathrm{pH}, n=3)$

peak displayed by the untreated centrate sample solution also corresponded to large particles $(133 \mu \mathrm{m})$. In contrast, small particles were reported for untreated $\mathrm{R} 100+50+5$ solutions (composed of molecules between 5 and $50 \mathrm{kDa}$ ), with the highest peak measured at $5 \mu \mathrm{m}$. Following sonication, the large particles reported for the untreated centrate and R100 solutions were broken down into smaller ones, with major peaks reported at $4 \mu \mathrm{m}$ for both samples. The sonication process did not significantly alter the particle size distribution of R $100+50+5$, with the major peak remaining at $5 \mu \mathrm{m}$.

The confocal micrographs confirmed the results obtained by laser light diffraction. Fungal cell and small hyphal debris were observed in the centrate (micrographs not shown). Due to the complex composition of the centrate, a succession of ultrafiltration steps was designed to separate large centrate components (including fungal cell and hyphal debris and large molecular aggregates) from small molecules and oligomeric aggregates to assess the functional contribution of each fraction, using the unfiltered centrate as reference. Much larger hyphal structures were observed in R100 (composed of material larger than $100 \mathrm{kDa}$ ) (Fig. 3a), resulting from the aggregation of the hyphal debris present in the centrate during their retention on the $100 \mathrm{kDa}$ ultrafiltration membrane. As previously postulated, the aggregation process observed could have resulted from the pressure exerted on the ultrafiltration membrane-retained material and/or from the temperature increase occurring during ultrafiltration [9]. Confocal micrographs of sonicated R100 solutions showed that these large hyphal aggregates were broken down into smaller fragments as a result of the sonication process (Fig. 3b, c), supporting the view that the large structures observed in R100 following ultrafiltration formed due to interaction between smaller hyphal fragments.

The successive ultrafiltration steps resulted in an increase in nitrogen-containing material (NCM): $47.9 \%$ (centrate), $54.0 \%(\mathrm{R} 100)$ and $70.4 \%(\mathrm{R} 100+50+5)$. The NCM contents obtained for these three streams proved similar to the ones measured in our previous study $(47.3 \%, 56.7 \%$ and $71.6 \%$ ) [9]. Following the $100 \mathrm{kDa}$ ultrafiltration step,
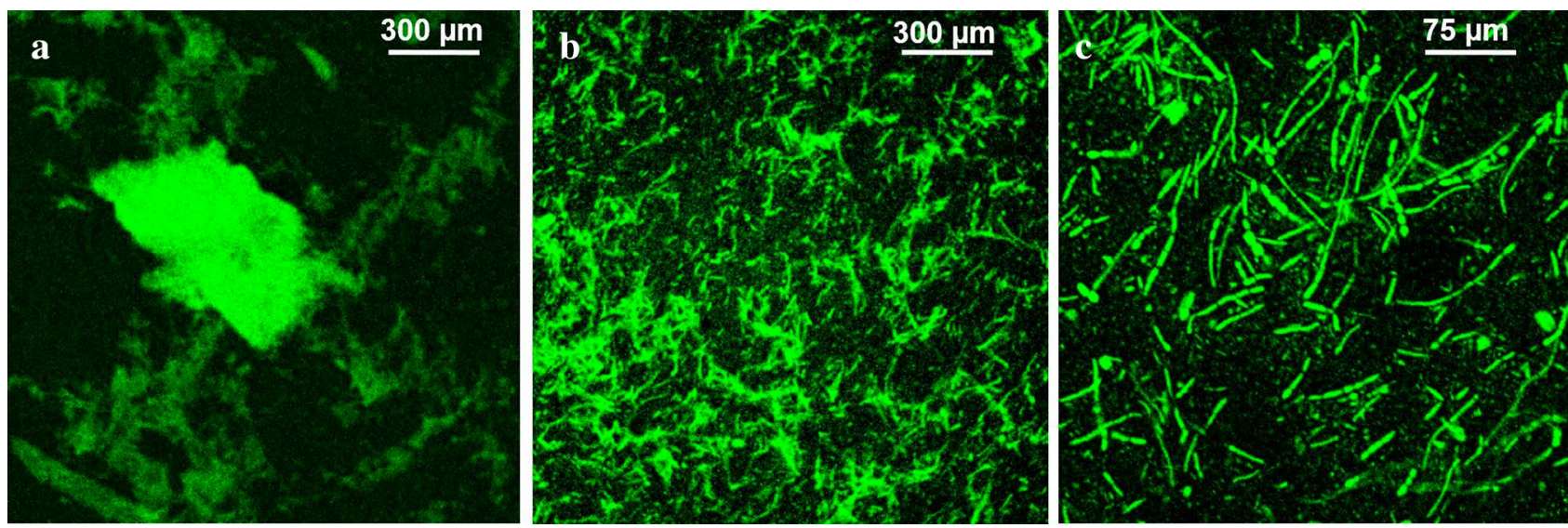

Fig. 3 Confocal microscopy of untreated and sonicated R100 solutions $[1 \% \mathrm{w} / \mathrm{w}$ NCM, original $\mathrm{pH}$, Rhodamine, magnification $\times 10(\mathbf{a}$, b) or $\times 40(\mathbf{c})]$. a R100, b sonicated R100, c sonicated R100 
the retention and aggregation of hyphal debris in R100 (observed in Fig. 3a) concentrated nitrogen-containing cell wall and cell membrane constituents (including phospholipids, sterols, glycosphingolipids, sphingomyelins, chitin, chitosan and glycoproteins) and contributed to the NCM increase in this sample. Following freeze-drying, the weight of sample obtained for the R $100+50$ sample (composed of molecules between 50 and $100 \mathrm{kDa}$ ) was very low and insufficient to test the functional profile of this fraction. The final filtrate obtained (filtrate $100+50+5$ ) did not prove functional (results not shown), indicating that the molecules smaller than $5 \mathrm{kDa}$ initially present in the untreated centrate did not contribute to its functionality.

At the micrometre level, both untreated centrate and R100 solutions displayed a major peak at $237 \mathrm{~nm}$, with an additional peak reported at $376 \mathrm{~nm}$ for R100 (Fig. 4a). Such particle sizes corresponded to molecular aggregates including protein oligomers. In contrast, the highest peak observed for the untreated R100+50+5 sample was reported at $1 \mathrm{~nm}$, corresponding to small molecules including protein monomers (Fig. 4b). This $1 \mathrm{~nm}$ peak was also observed in the untreated centrate solution. Following sonication, major additional peaks were observed at 2 and $3 \mathrm{~nm}$, respectively, for the centrate and R100 samples, while the $376 \mathrm{~nm}$
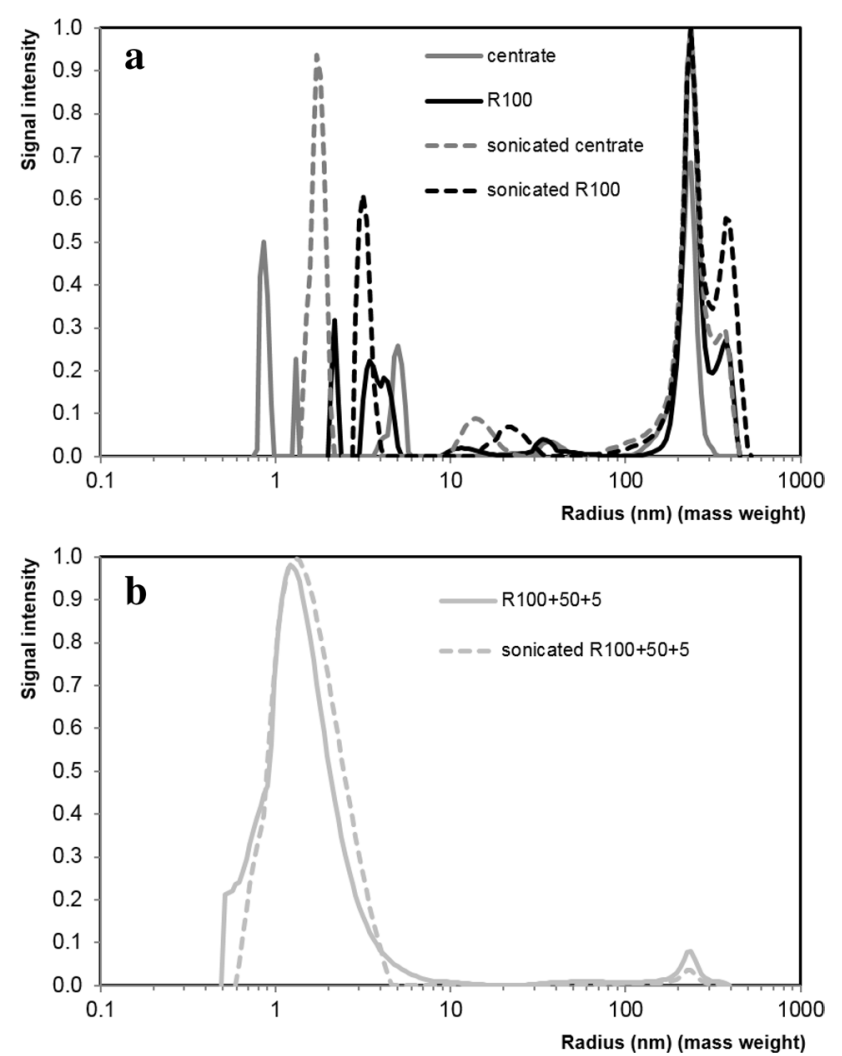

Fig. 4 Particle size distribution of untreated and sonicated centrate fraction solutions measured by dynamic light scattering $(1 \% \mathrm{w} / \mathrm{w}$ $\mathrm{NCM}$, original $\mathrm{pH}, n=3$ ). a Centrate and $\mathrm{R} 100, \mathbf{b} \mathrm{R} 100+50+5$ peak increased for both centrate and R100 samples and the $237 \mathrm{~nm}$ increased for the centrate. The appearance of the 2 and $3 \mathrm{~nm}$ peaks suggested that the sonication process resulted in the rupturing of cell walls and the release of intracellular molecules and/or cell wall and cell membrane components (including phospholipids, chitin, chitosan, protein monomers or oligomers and small nucleoside or nucleoside chains). The cell walls would have been left largely intact during the ultrafiltration process, explaining the absence of the 2 and $3 \mathrm{~nm}$ peaks in untreated centrate and R100. However, the increase of the high particle size peaks $(376 \mathrm{~nm}$ in both centrate and R100 and $237 \mathrm{~nm}$ in centrate) coupled with the decrease or disappearance of lower particle size peaks $(1-5 \mathrm{~nm})$ in both centrate and R100 following sonication also suggested the additional aggregation of a number of 1-5 nm molecular species (including protein monomers or oligomers initially present in the samples and/or released from cells during sonication) into the larger molecular components (376 and/or $237 \mathrm{~nm}$ ) as a result of the sonication process. Aggregation of proteins including bovine serum albumin, myoglobin and lysozyme following sonication has previously been reported as a result of enhanced intermolecular interactions including disulphide bridges facilitated by the unfolding of the native state of these proteins caused by cavitation [20]. The sonication process did not significantly alter the particle size distribution of $\mathrm{R} 100+50+5$, with the major peak remaining at $1 \mathrm{~nm}$.

\section{Foaming properties of untreated and sonicated solutions}

Untreated R100 foams displayed a lower foaming ability but higher foam stability than the untreated centrate (Fig. 5) in accordance with our previous findings [9]. The sonication process resulted in an increase in foaming ability for the centrate and R100 samples. The stability of the sonicated

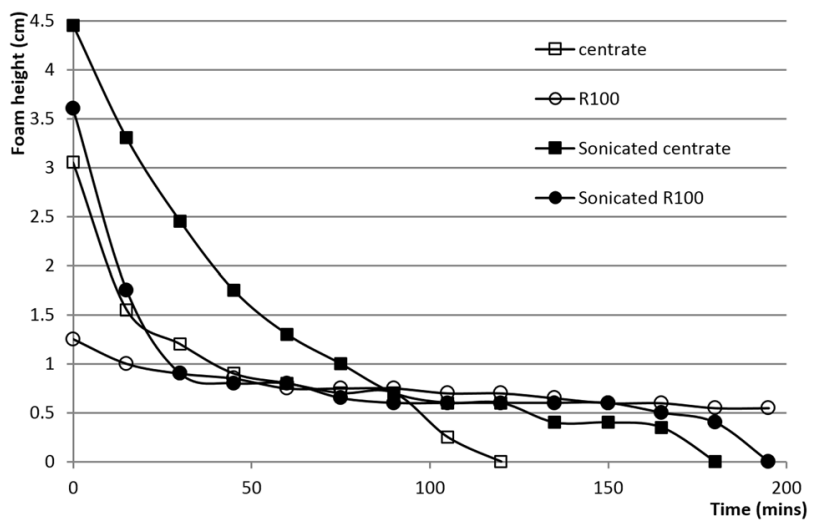

Fig. 5 Foaming ability and foam stability profiles of untreated and sonicated centrate fractions (frothing assay, $1 \% \mathrm{w} / \mathrm{w} \mathrm{NCM}$, original $\mathrm{pH}, n=3$ ) 
R100 foam proved high, however, not as high as that of the untreated R100 foam. Sonicated R100 displayed higher foaming ability and stability than a sonicated commercial whey protein concentrate (WPC) control and sonicated $\mathrm{R} 100+50+5$ (results not shown).

High densities of air bubbles were observed in untreated and sonicated centrate foams (Fig. 6a, b) in agreement with the high foaming abilities reported for centrate solutions (Fig. 5) and with previous results obtained on untreated centrate [9]. In contrast few air bubbles were reported for R100 foams, although sonicated R100 foams (Fig. 6d) displayed a higher concentration of air bubbles than untreated R100 ones (Fig. 6c), which correlated with the increase in foaming ability measured for R100 following sonication (Fig. 5). The poor foaming ability reported for untreated R100 was in agreement with our previous findings [9].

Confocal micrographs also showed that air bubbles in sonicated R100 foams were trapped in a less dense network of hyphal fragments (Fig. 6d) than in untreated R100 foams (Fig. 6c) due to the partial breakdown of R100 hyphal aggregates during sonication as observed in Fig. 3b, c. This in turn allowed a higher number of air bubbles to be entrapped thus explaining the higher foaming ability of R100 following sonication. The dense hyphal network observed in untreated R100 solutions (Fig. 3a) was previously associated with high viscosity [9], which only allowed a limited number of air bubbles to be formed and transported within the liquid, leading to a poor foaming ability. Such a mechanism agreed with the existing literature in which highly viscous fermentation media resulted in issues with gas-liquid mass transfer for the filamentous fungus Aspergillus terreus [21] and in which sonication of the fermentation broth of the fungus Cordyceps sinensis $C s-H K 1$ caused a dramatic reduction of viscosity [22]. On the other hand, the denser, more viscous hyphal network observed in untreated R100 foams better prevented the destabilisation of the air bubbles formed than in sonicated R100 foams by limiting their breakdown, probably through reduced drainage in the plateau borders, leading to a higher foam stability as reported in Fig. 5.

In addition, as highlighted in the laser light diffraction results (Fig. 2a), the breakdown of the R100 hyphal aggregates during sonication further released surface-active molecules, molecular aggregates and cell debris which could also have contributed to the high foaming ability of
Fig. 6 Confocal microscopy of centrate fraction interfaces prepared by frothing $(1 \% \mathrm{w} / \mathrm{w}$ $\mathrm{NCM}$, original $\mathrm{pH}$, Rhodamine, magnification $\times 10$ ). a Centrate foam, $\mathbf{b}$ sonicated centrate foam, $\mathbf{c}$ R100 foam, $\mathbf{d}$ sonicated R100 foam
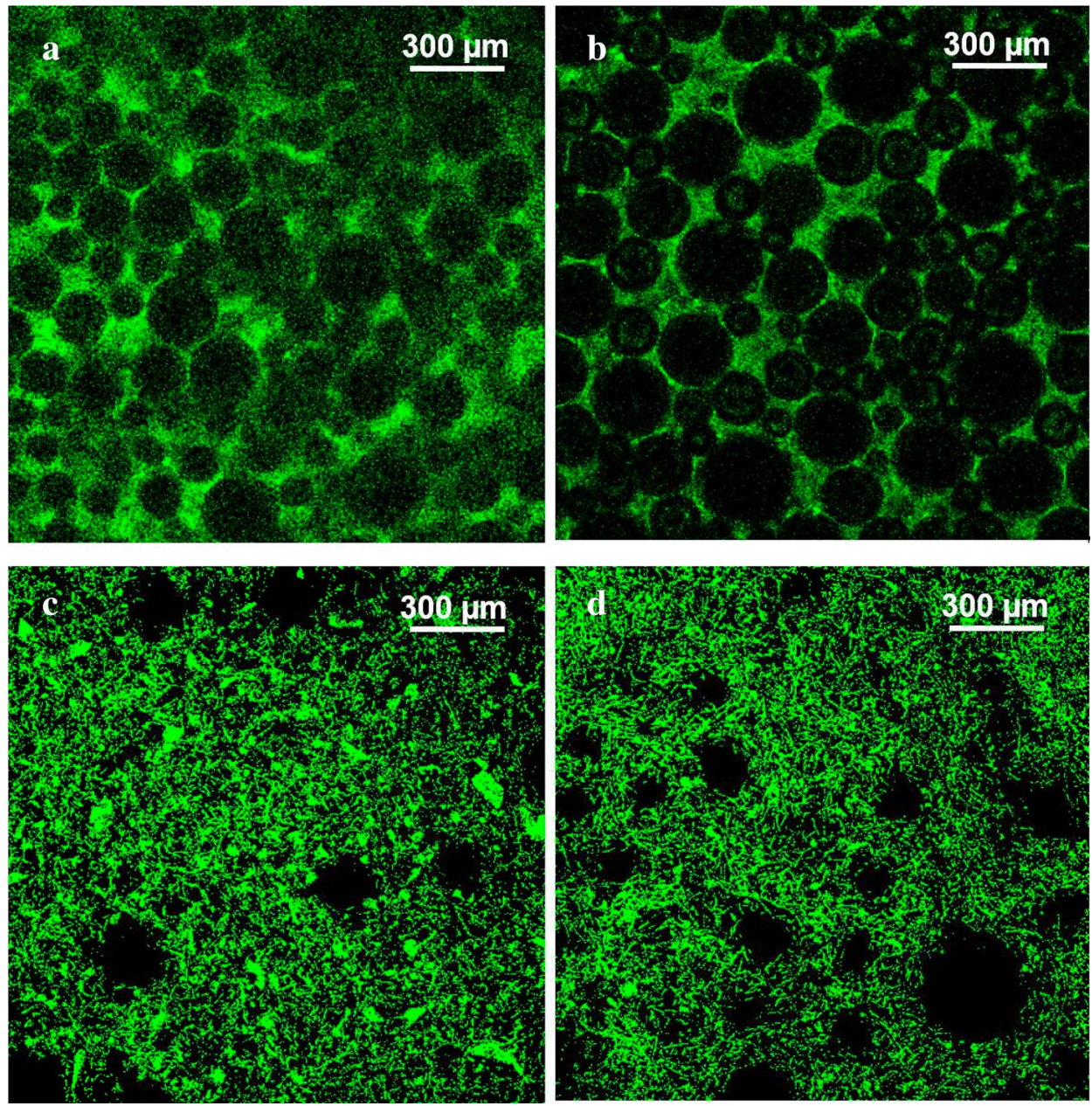
sonicated R100. Similarly, the rupturing of fungal cell walls in sonicated centrate and R100 solutions as suggested by the dynamic light scattering results (Fig. 4a) further released surface-active molecules, contributing to the increase in both foaming ability and stability of the centrate. Our previous study highlighted the presence of surface-active material in centrate fractions [9]. A number of proteins with known foaming properties were identified in centrate and R100. A cerato-platanin was concentrated in the $\mathrm{R} 100$ fraction in comparison with the centrate and the serpin SERPB1 was detected in both samples. The cerato-platanin EPL1 from the fungus Trichoderma atroviride was previously reported to form ordered self-assembled layers at the air/water interface [23] and hydrophobic/hydrophilic interfaces [24], while serpins Z4 and Z7 from barley have been characterised as foampositive proteins in beer $[25,26]$. A number of metabolites with known foaming properties were also previously identified in centrate [9], including cell wall and cell membrane constituents such as chitin and chitosan [27, 28] and intracellular metabolites such as monoglycerides and diglycerides [29], glycosyldiglycerides [30], triterpenoid and steroidal saponins [31], rhamnolipids [32] and fatty amides [33].

\section{Emulsifying properties of untreated and sonicated solutions}

Untreated R100 emulsions displayed a smaller oil droplet size than the untreated centrate, R100+50+5 (Fig. 7a) and WPC control ones (results not shown), which was in accordance with our previous findings [9]. Sonicated R100 emulsions showed a smaller oil droplet size (mean oil droplet size of $13.57 \mu \mathrm{m})$ than untreated R100 ones $(18.61 \mu \mathrm{m})$, however, the sonication process did not yield a reduction in droplet size for centrate and R $100+50+5$. The mean oil droplet size in sonicated R100 emulsions also proved smaller than in sonicated WPC ones ( $23.75 \mu \mathrm{m}$, results not shown). Confocal micrographs confirmed the smaller oil droplet size distribution observed in sonicated R100 emulsions (Fig. 8b) in comparison with centrate and R100+50+5 (Fig. 8a, c).

A ring of small hyphal fragments was visible around oil droplets in untreated R100 emulsions (Fig. 9b1, c1), suggesting a role for the hyphal fragments in the formation and stabilisation of the emulsions. Similar observations were reported for sonicated R100 emulsions, however, due to the high inherent turbidity of sonicated R100 emulsions, the micrographs did not appear as clear as untreated R100 ones at high magnification and the latter were chosen for illustration purpose in Fig. 9. The size of the small hyphal fragments $(1-4 \mu \mathrm{m})$ observed around oil droplets in sonicated R100 emulsions matched with the largest particle size peak reported at $4 \mu \mathrm{m}$ in sonicated R100 solutions (Fig. 2a), while the wider size range of fragments $(2-18 \mu \mathrm{m})$ observed around oil droplets in untreated R100 emulsions (Fig. 9b1,
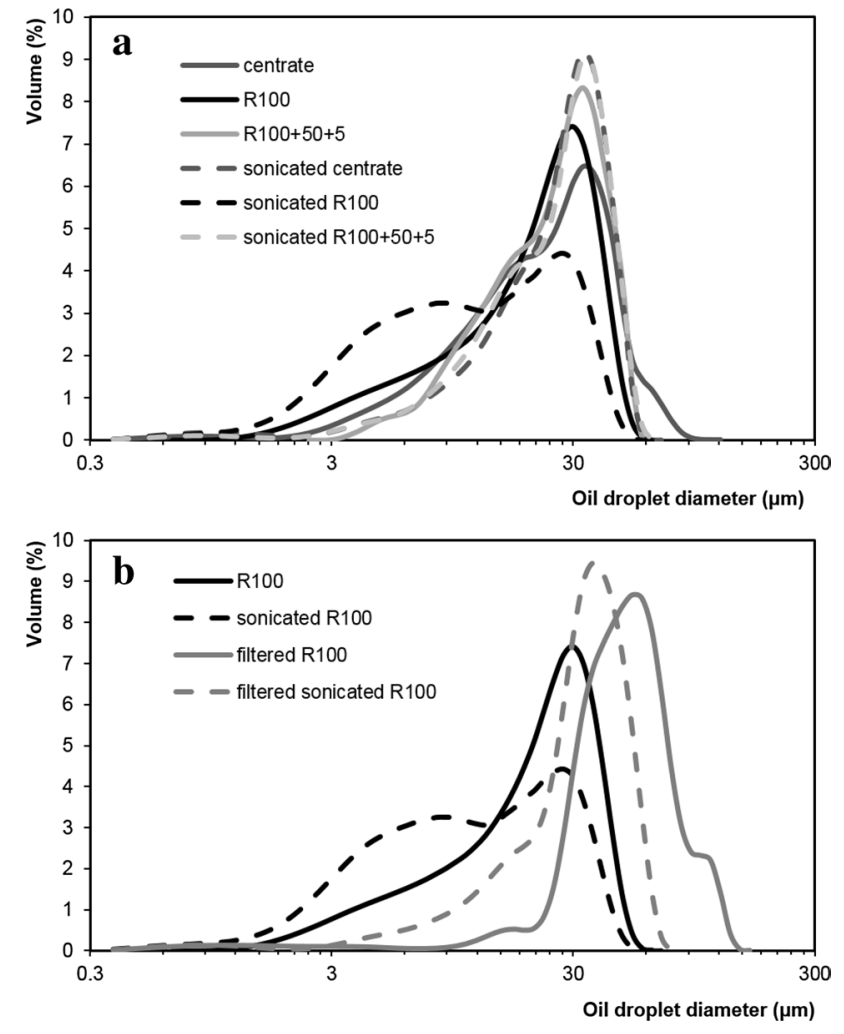

Fig. 7 Oil droplet size distribution of untreated and sonicated (a) and filtered untreated and sonicated centrate fraction emulsions (b) $(1 \%$ w/w NCM, original $\mathrm{pH}, n=3$ )

c1) was reported at low level in the untreated R100 sample (Fig. 2a). The shapes and sizes of bacterial cells, viruses and spores fall within the range for Pickering stabilisation of biphasic dispersions including foams and emulsions [34]. This in turn suggests that, based on their hydrophobicity, hyphal fragments present in R100 and/or released during the sonication and emulsifying processes contributed to the formation and stabilisation of small oil droplets in untreated and sonicated R100 emulsions through a Pickering-type stabilisation. A partially hydrophobic moss spore (Lycopodium clavatum) has been shown to stabilise oil-in-water emulsions [35], while the ability of certain intact bacterial cells to stabilise oil-in-water and water-in-oil emulsions has also been reported [36]. In a particle-stabilised R100 emulsion system, the smaller hyphal debris reported in sonicated R100 in comparison with untreated R100 would appear to contribute to formation of smaller oil droplets than in untreated $\mathrm{R} 100$ emulsions, in agreement with the results presented in Fig. 7a. Pickering stabilisation by natural biological particles has previously been reported, with bacterial cellulose nanocrystals [37] and cocoa particles [38] reported to form and stabilise oil-in-water emulsions. Pickering stabilisation by hyphal fragments could also explain the high foaming properties of untreated and sonicated R100 reported in 

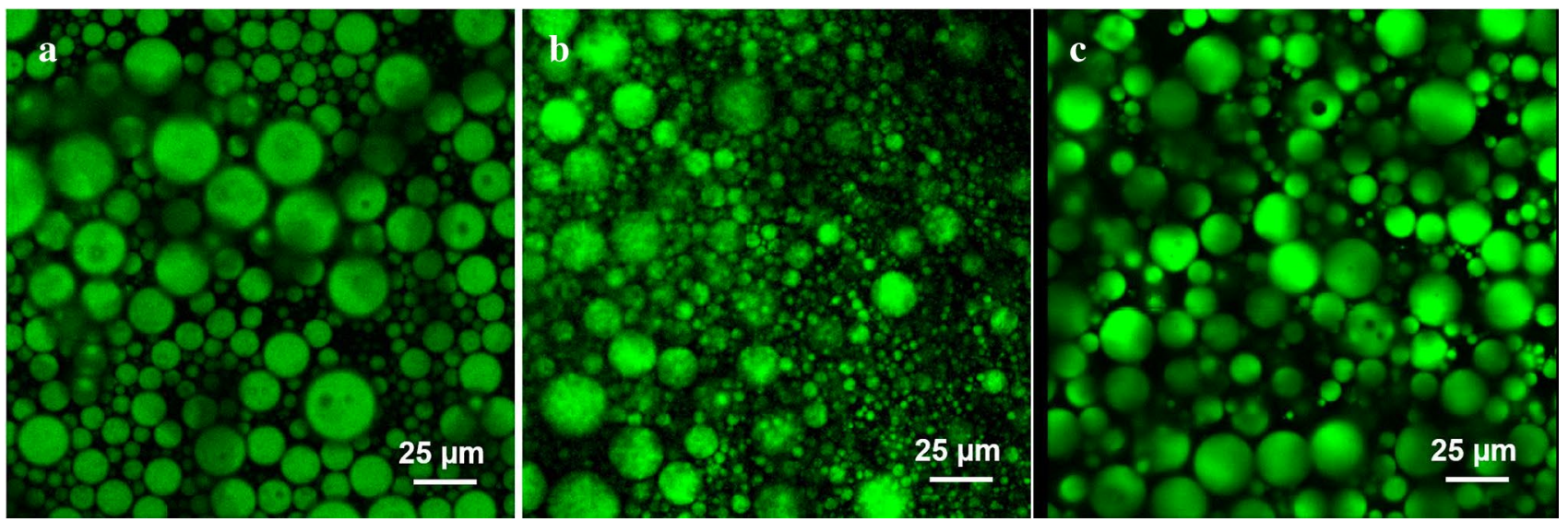

Fig. 8 Confocal microscopy of sonicated centrate fraction emulsions $(1 \% \mathrm{w} / \mathrm{w}$ NCM, original $\mathrm{pH}$, Nile Red, magnification $\times 63)$. a Centrate, $\mathbf{b}$ $\mathrm{R} 100, \mathrm{c} \mathrm{R} 100+50+5$

Fig. 5. A correlation between foam stability and cell surface hydrophobicity has previously been reported for different strains of Acinetrobacter calcoaceticus [39]. Moreover, the hyphal network observed in untreated and sonicated R100 appeared to be entrapping oil droplets (Fig. 9a1), which was in agreement with the high emulsion stability reported for untreated R100 in our previous study [9].

In addition to the release of hyphal fragments from R100 aggregates during sonication and emulsification, the rupturing of cell walls as suggested in Fig. 4a also released molecules and molecular aggregates with known emulsifying properties, further contributing to the formation and stabilisation of small oil droplets. Emulsion-positive compounds previously reported in the centrate [9] included cell wall and cell membrane constituents (such as chitin and chitosan $[27,28]$ and phospholipids [40]) and intracellular molecules (such as monoglycerides and diglycerides [29], glycosyldiglycerides [30], triterpenoid and steroidal saponins [31], rhamnolipids [32] and fatty amides [33]).

In parallel, emulsions were prepared with untreated and sonicated R100 solutions that were filtered using a $200 \mathrm{~nm}$ cut-off membrane prior to emulsification. These solutions produced larger oil droplet size distributions (respective mean oil droplet sizes of 54.70 and $33.57 \mu \mathrm{m}$ ) than their non-filtered counterparts (Fig. 7b). These results highlighted that, in addition to the small hyphal fragments identified in Fig. 9b1, c1, the larger hyphal fragments observed in Fig. 9a1 also contributed to the emulsifying properties of sonicated R100 possibly by physically separating and limiting the movement of oil droplets.

The untreated $\mathrm{R} 100+50+5$ solution and all the sonicated centrate fraction solutions (centrate, R100 and $\mathrm{R} 100+50+5$ ) displayed a major particle size peak at $4 \mu \mathrm{m}$ when measured by laser light diffraction at a refractive index of 1.474 corresponding to sunflower oil (Fig. 2b). A major oil droplet size peak was reported at $8 \mu \mathrm{m}$ for sonicated R100 emulsions (Fig. 7); however, this peak was absent for all other emulsion samples, showing that the presence of hyphal material in emulsions prepared with centrate fractions did not influence the measurement of their oil droplet sizes and distributions by laser light diffraction.

\section{Characterisation of the reduced-oil emulsions}

The mixing of sonicated R100 dispersion with either mixed or sonicated R100 emulsions (Fig. 1) resulted in a decrease of their oil droplet size distributions: from 18.61 to $15.19 \mu \mathrm{m}$ for the mixed R100 emulsion and from 13.57 to $8.50 \mu \mathrm{m}$ for the sonicated R100 emulsion (Fig. 10a). The 50\% oilreduced sonicated R100 emulsion displayed the lowest mean droplet size of all emulsions tested $(8.50 \mu \mathrm{m})$. Similarly, the mixed and sonicated oil-reduced centrate, R100+50+5 and WPC emulsions showed smaller oil droplet sizes than their full-oil counterparts (R100 $+50+5$ and WPC results not shown), but not to the extent as the differences reported between oil-reduced and full-oil R100 emulsions. For oilreduced centrate emulsions, the oil droplet size diameter decreased from 27.70 to $17.80 \mu \mathrm{m}$ for the mixed centrate emulsion and from 27.29 to $21.90 \mu \mathrm{m}$ for the sonicated centrate emulsion. For all emulsions, the R100 samples displayed the lowest oil droplet sizes. In contrast to the results obtained with the addition of sonicated dispersions to emulsions, the addition of stirred centrate, R100 or R $100+50+5$ dispersions to either mixed or sonicated emulsions did not reduce their oil droplet size (results not shown). The 50\% oil emulsion controls prepared with untreated and sonicated centrate fractions displayed similar oil droplet size distributions to their full-oil counterparts (results not shown), showing that the decrease in oil droplet size reported for oil-reduced emulsions was due to the mixing with additional 
Fig. 9 Confocal microscopy of untreated R100 emulsions $(1 \% \mathrm{w} / \mathrm{w} \mathrm{NCM}$, original $\mathrm{pH}$, rhodamine, magnification $\times 63$ ). a1-c2 Examples of oil droplets surrounded by hyphal fragments
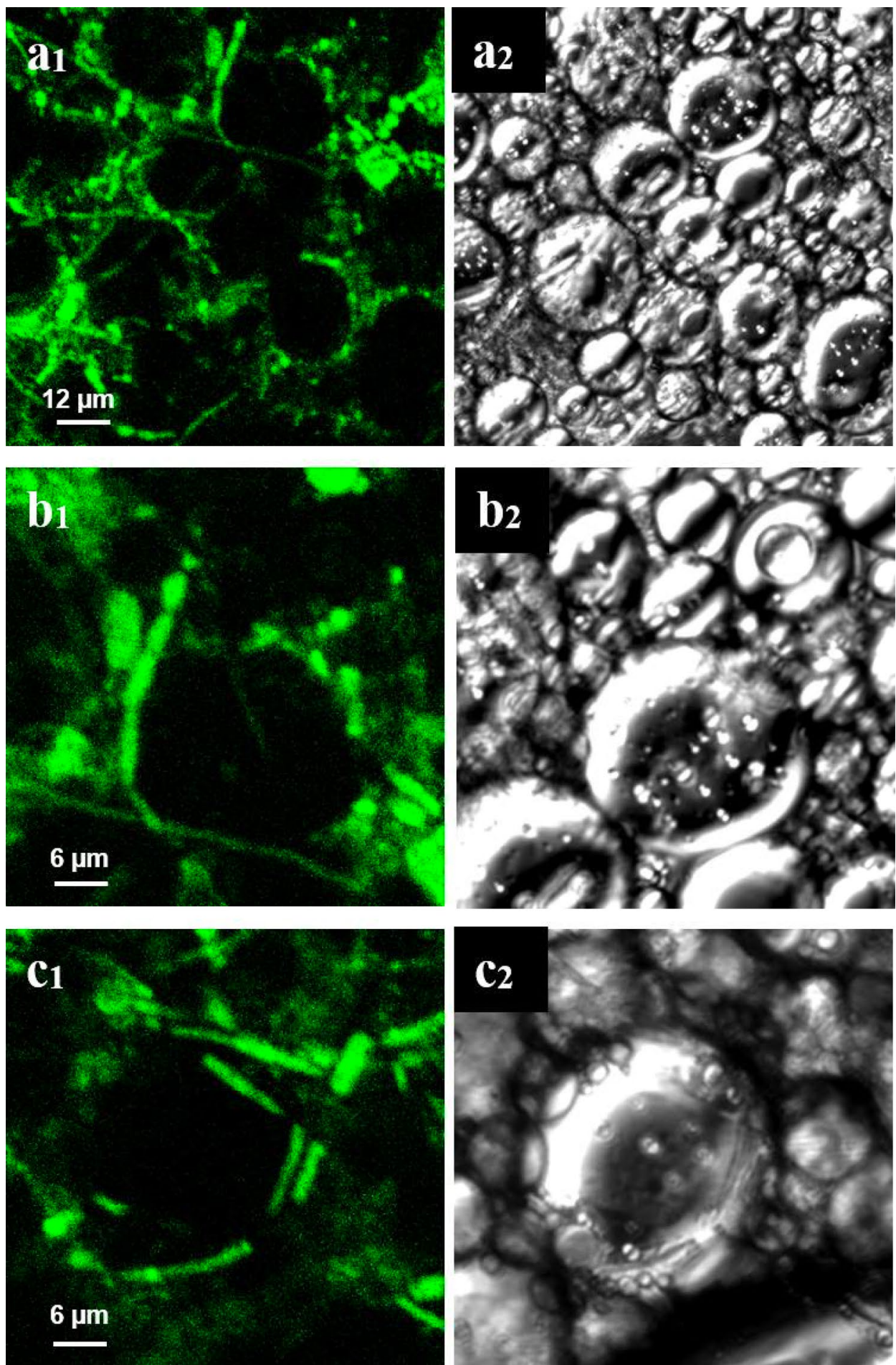

centrate fraction material rather than to the reduction in oil content.

The light micrographs confirmed the smaller oil droplet size distributions reported for the $50 \%$ oil-reduced R100 emulsions (mixed emulsion/sonicated dispersion and sonicated emulsion/sonicated dispersion) (Fig. 11). In particular, the micrograph 11 of Fig. 11 showed the very low droplet size distribution achieved when mixing a sonicated R100 emulsion with a sonicated R100 dispersion.

These results indicated that the addition of small hyphal fragments or other surface-active molecules present in sonicated R100 to the particle-stabilised R100 emulsion model observed in Fig. 9 resulted in the formation and stabilisation of smaller oil droplets. The presence of this material is likely 

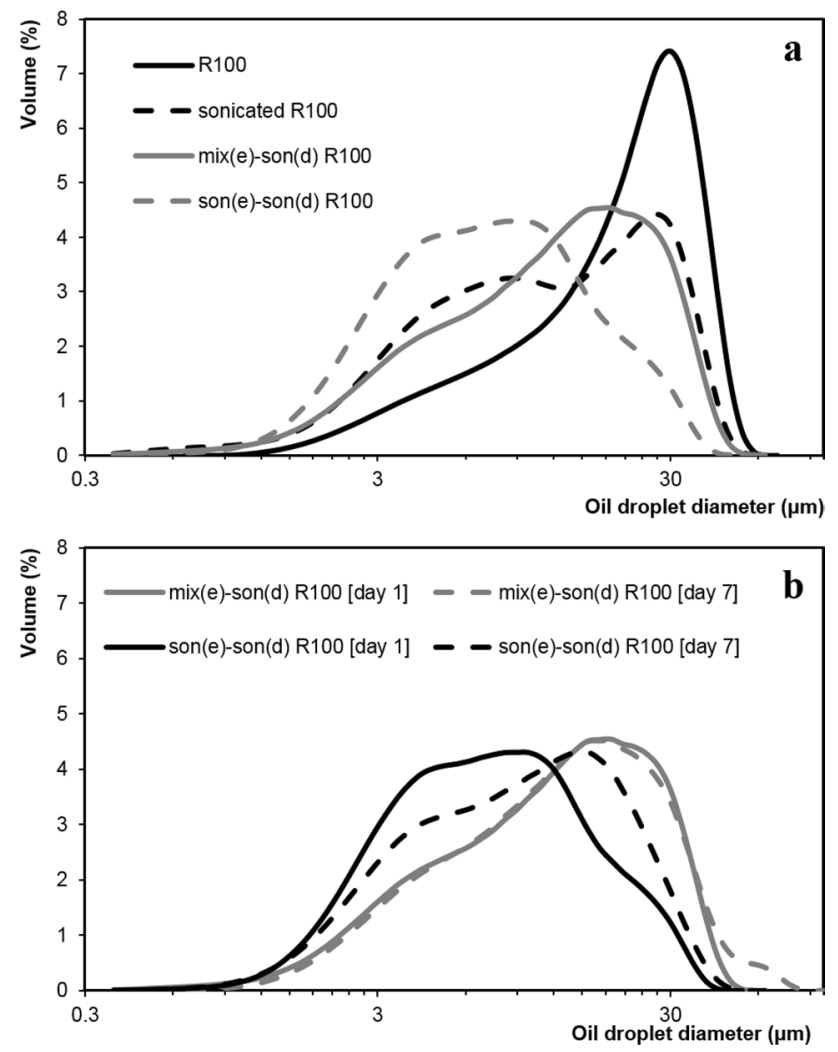

Fig. 10 Oil droplet size distribution of untreated, sonicated and oilreduced R100 emulsions (a) and of oil-reduced R100 emulsions over 7 days of storage (b) $(1 \% \mathrm{w} / \mathrm{w} \mathrm{NCM}$, original $\mathrm{pH}, n=3)$

to have contributed to the smaller droplet sizes by reducing the extent of droplet coalescence. The oil droplet size of the $50 \%$ oil-reduced R100 emulsions (mixed emulsion/sonicated dispersion and sonicated emulsion/sonicated dispersion) remained small and stable over a 7-day period: from 15.19 to $16.56 \mu \mathrm{m}$ for the mixed R100 emulsion and from 8.50 to $11.97 \mu \mathrm{m}$ for the sonicated R100 emulsion (Fig. 10b). The reduction of oil droplet size in an oil-reduced formulation has previously been reported to replicate the mouthfeel of a full-fat formulation [3, 4], highlighting the potential of sonicated R100 as both emulsifier and oil-lowering agent in emulsion-based food products.

\section{Conclusions}

This study highlighted the potential to modulate the structure, emulsifying and foaming properties of a functional extract (retentate 100 or R100) from the Quorn fermentation co-product by sonication. Sonicating an R100 solution led to the breakdown of the large hyphal structure characteristic of untreated R100 into smaller fragments.

Foams prepared with sonicated R100 displayed a higher foaming ability than with untreated R100 as well as a high foam stability, although lower than untreated R100 ones. The results indicated that the looser hyphal network observed in sonicated R100 foams and the associated release of small hyphal fragments and other surface-active molecules allowed for a higher number of air bubbles to be formed but did not stabilise them as well as the dense hyphal network observed in untreated R100 foams.

Oil-in-water emulsions prepared with sonicated R100 displayed smaller oil droplet size distributions than with untreated R100. Confocal micrographs of R100 emulsions suggested a Pickering-type stabilisation by small hyphal fragments released during sonication and emulsification. $50 \%$ oil-reduced R100 emulsions were prepared by mixing R100 emulsions with a sonicated R100 solution. This further addition of small hyphal fragments and other surfaceactive molecules resulted in even smaller oil droplet size distributions.

These results highlighted the potential of sonicated R100 as foaming agent, emulsifier and oil-lowering agent for the food industry. Additional studies will assess if the smaller oil droplet size measured in oil-reduced formulations allows to maintain the same creaminess and satiety sensation as fullfat formulations. Future studies will also be carried out to further understand the contribution of the hyphal fragments to the formation and stabilisation of emulsions and foams and to determine their optimal concentration and size for functionality. Finally, this work highlights the possibility to investigate the impact of sonication on the mycelium biomass and functionality of the other Quorn fermentation process streams (fermentation broth and RNA-reduced broth). 

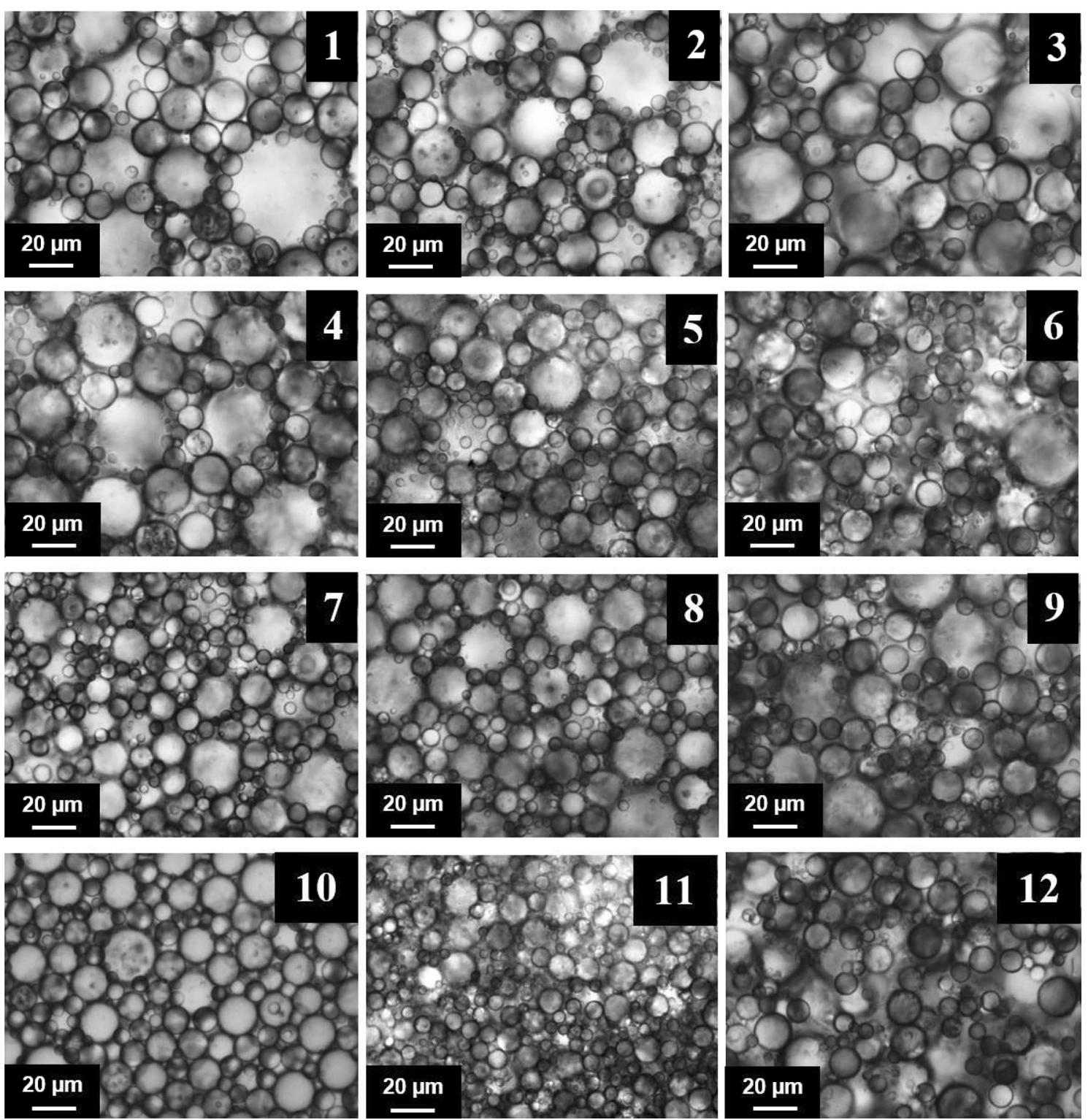

Fig. 11 Bright-field microscopy of full-oil and oil-reduced centrate fraction emulsions $(1 \% \mathrm{w} / \mathrm{w} \mathrm{NCM}$, magnification $\times 50)$. (1) $\operatorname{mix}(\mathrm{e})$ centrate, (2) $\operatorname{mix}(\mathrm{e}) \mathrm{R} 100$, (3) $\operatorname{mix}(\mathrm{e}) \mathrm{R} 00+50+5$. (4) son(e) centrate, (5) son(e) R100, (6) son(e) R00+50+5. (7) mix(e)-son(d) cen-

Acknowledgements The authors wish to thank Dr Tim Finnigan and Dr Sue Gordon from Marlow Foods for their support during this project. This work was supported by the Engineering and Physical Sciences Research Council [Grant number EP/J501682/1 (Foaming and Fat Replacer Ingredients].

\section{Compliance with ethical standards}

Conflict of interest There are no conflicts of interest to declare.

Compliance with ethics requirements This article does not contain any studies with human participants or animals performed by any of the authors. trate, (8) $\operatorname{mix}(\mathrm{e})-\operatorname{son}(\mathrm{d}) \mathrm{R} 100$, (9) $\operatorname{mix}(\mathrm{e})-\operatorname{son}(\mathrm{d}) \mathrm{R} 00+50+5$. (10) son(e)-son(d) centrate, (11) son(e)-son(d) R100, (12) son(e)-son(d) $\mathrm{R} 00+50+5$. $e$ emulsion, $d$ dispersion, mix mixed, son sonicated

Open Access This article is licensed under a Creative Commons Attribution 4.0 International License, which permits use, sharing, adaptation, distribution and reproduction in any medium or format, as long as you give appropriate credit to the original author(s) and the source, provide a link to the Creative Commons licence, and indicate if changes were made. The images or other third party material in this article are included in the article's Creative Commons licence, unless indicated otherwise in a credit line to the material. If material is not included in the article's Creative Commons licence and your intended use is not permitted by statutory regulation or exceeds the permitted use, you will need to obtain permission directly from the copyright holder. To view a copy of this licence, visit http://creativecommons.org/licenses/by/4.0/. 


\section{References}

1. Food and Agriculture Organization of the United Nations (2010) Fats and fatty acids in human nutrition: report of an expert consultation. FAO Food Nutr 91:1-166

2. World Health Organization (2003) Diet, nutrition and the prevention of chronic diseases. Technical report no. 916.

3. Lett AM, Norton JE, Yeomans MR (2003) Emulsion oil droplet size significantly affects satiety: a pre-ingestive approach. Appetite 96:18-24

4. Lett AM, Yeomans MR, Norton IT, Norton JE (2016) Enhancing expected food intake behaviour, hedonics and sensory characteristics of oil-in-water emulsion systems through microstructural properties, oil droplet size and flavour. Food Qual Prefer 47(B):148-155

5. Denny A, Aisbitt B, Lunn J (2008) Mycoprotein and health. Br Nutr Bull 33:298-310

6. Edelman J, Fewell A, Solomons GL (1983) Myco-protein-a new food. Nutr Abstr Rev Clin Nutr 53:471-480

7. Finnigan TJA, Lemon M, Allen B, Patton I (2010) Mycoprotein LCA and food 2030. Aspect Appl Biol 102:81-90

8. Ward PN (1996) A process for the reduction of nucleic acid content for a fungus imperfectus, WO Patent 95/23843.

9. Lonchamp J, Clegg PS, Euston SR (2019) Foaming, emulsifying and rheological properties of extracts from a co-product of the Quorn fermentation process. Eur Food Res Technol 245(9):1825-1839

10. Gallo G, Ferrara L, Naviglio D (2018) Application of ultrasound in food science and technology: a perspective. Foods 7:164

11. Feng H, Lee H (2011) Effect of power ultrasound on food quality. In: Feng H, Barbosa-Cánovas GV, Weiss J (eds) Ultrasound technologies for food and bioprocessing. Springer, New York

12. Clark JP (2008) An update on ultrasonics. Food Technol 26:75-77

13. Tchuenbou-Magaia FL, Norton IT, Cox PW (2009) Hydrophobins stabilised air-filled emulsions for the food industry. Food Hydrocoll 23:1877-1885

14. Tchuenbou-Magaia FL, Al-Rifai N, Norton IT, Cox PW (2011) Suspensions of air cells with cysteine-rich protein coats: airfilled emulsions. J Cell Plast 47(3):217-232

15. Suslick KS, Grinstaff MW, Kompany E, Wong M (1994) Characterization of sonochemically prepared proteinaceous microspheres. Ultrason Sonochem 1:S65-S68

16. Lynch JM, Barbano DM, Fleming JR (1998) Indirect and direct determination of the casein content of milk by Kjeldahl nitrogen analysis: collaborative study. J AOAC Int 81:763-774

17. Sadler MJ (2003) Mycoprotein. In: Caballero B, Trugo M, Finglas PM (eds) Encyclopedia of food sciences and nutrition, 2nd edn. Academic Press, Cambridge

18. Hayakawa O, Nakahira K, Tsubaki JI (1995) Estimation of the optimum refractive index by the laser diffraction and scattering method on the raw material of fine ceramics. Adv Powder Technol 6:47-61

19. Saveyn H, Mermuys D, Thas O, van der Meeren P (2002) Determination of the refractive index of water-dispersible granules for use in laser diffraction experiments. Part Part Syst Charact 19:426-432

20. Stathopulos PB, Scholz GA, Hwang YM, Rumfeldt JAO, Lepock JR, Meiering EM (2004) Sonication of proteins causes formation of aggregates that resemble amyloid. Protein Sci 13(11):3017-3027

21. Porcel EMR, Casas Lopez JL, Sanchez Perez JA, Fernandez Sevilla JM, Chisti Y (2005) Effects of pellet morphology on broth rheology in fermentations of Aspergillus terreus. Biochem Eng J 26:139-144
22. Cheung YC, Liu XX, Wang WQ, Wu JY (2015) Ultrasonic disruption of fungal mycelia for efficient recovery of polysaccharideprotein complexes from viscous fermentation broth of a medicinal fungus. Ultrason Sonochem 22:243-248

23. Frischmann A, Neudl S, Gaderer R, Bonazza K, Zach S, Gruber S, Spadiut O, Friedbacher G, Grothe H, Seidl-Seiboth V (2013) Self-assembly at air/water interfaces and carbohydrate binding properties of the small secreted protein EPL1 from the fungus Trichoderma atroviride. J Biol Chem 288:4278-4287

24. Bonazza K, Gaderer R, Neudl S, Przylucka A, Allmaier G, Druzhinina IS, Grothe H, Friedbacher G, Seidl-Seiboth V (2015) The fungal cerato-platanin protein EPL1 forms highly ordered layers at hydrophobic/hydrophilic interfaces. Soft Matter 11(9):1723-1732

25. Li X, Jin Z, Gao F, Lu J, Cai G, Dong J, Yu J, Yang M (2014) Characterization of barley serpin $\mathrm{Z} 7$ that plays multiple roles in malt and beer. J Agric Food Chem 62(24):5643-5650

26. Specker C, Niessen L, Vogel RF (2014) In vitro studies on the main beer protein $\mathrm{Z} 4$ of Hordeum vulgare concerning heat stability, protease inhibition and gushing. J Inst Brew 120:85-92

27. Lapasin R, Stefancic S, Delben F (1996) Rheological properties of emulsions containing soluble chitosan. Agro Food Ind High Tech 7:12-17

28. Quintela S, Villarán MC, López De Armentia I, Elejalde E (2012) Ochratoxin a removal from red wine by several oenological fining agents: bentonite, egg albumin, allergen-free adsorbents, chitin and chitosan. Food Addit Contam Part A 29(7):1168-1174

29. Moonen H, Bas H (2004) Mono- and di-glycerides. In: Whitehurst RJ (ed) Emulsifiers in food technology. Blackwell Publishing Ltd, Oxford

30. Keller RCA, Orsel R, Hamer RJ (1997) Competitive adsorption behaviour of wheat flour components and emulsifiers at an airwater interface. J Cereal Sci 25:175-183

31. Kharkwal H, Panthari P, Pant MK, Kharkwal H, Kharkwal AC, Joshi DD (2012) Foaming glycosides: a review. IOSR J Pharm 2(5):23-28

32. Al-Ahmad K (2015) The definition, preparation and application of rhamnolipids as biosurfactants. Int J Nutr Food Sci 4(6):613-623

33. Xu W, Gu H, Zhu X, Zhong Y, Jiang L, Xu M, Song A, Hao J (2015) $\mathrm{CO}_{2}$-controllable foaming and emulsification properties of the stearic acid soap systems. Langmuir 31(21):5758-5766

34. Lam S, Velikov KP, Velev OD (2014) Pickering stabilization of foams and emulsions with particles of biological origin. Curr Opin Colloid Interface Sci 19(5):490-500

35. Binks BP, Clint JH, Mackenzie G, Simcock C, Whitby CP (2005) Naturally occurring spore particles at planar fluid interfaces and in emulsions. Langmuir 21(18):8161-8167

36. Dorobantu LS, Yeung AKC, Foght JM, Gray MR (2004) Stabilization of oil-water emulsions by hydrophobic bacteria. Appl Environ Microbiol 70(10):6333-6336

37. Kalashnikova I, Bizot H, Cathala B, Capron I (2011) New Pickering emulsions stabilized by bacterial cellulose nanocrystals. Langmuir 27:7471-7479

38. Gould J, Vieira J, Wolf B (2013) Cocoa particles for food emulsion stabilisation. Food Funct 4:1369-1375

39. Rosenberg M, Rosenberg E (1985) Bacterial adherence at the hydrocarbon-water interface. Oil Petrochem Pollut 2(3):155-162

40. Pichot R, Watson RL, Norton IT (2013) Phospholipids at the interface: current trends and challenges. Int J Mol Sci 14:11767-11794

Publisher's Note Springer Nature remains neutral with regard to jurisdictional claims in published maps and institutional affiliations. 